\title{
A alfabetização científica e tecnológica e o combate a disseminação de notícias falsas na pandemia do SARS-CoV-2
}

Scientific and technological literacy and combating the dissemination of fake news in the SARSCoV-2 pandemic Alfabetización científica y tecnológica y lucha contra la difusión de noticias falas en la pandemia SARS-CoV-2

Jorge Ricardo Almeida de Souza Filho

ORCID: https://orcid.org/0000-0003-1317-1100

Secretaria da Educação do Estado do Ceará, Brasil E-mail: jorge.filho1@ prof.ce.gov.br

Ana Karine Portela Vasconcelos ORCID: https://orcid.org/0000-0003-1087-5006 Instituto Federal de Educação, Ciência e Tecnologia do Ceará, Brasil E-mail: karine@ifce.edu.br

Vicente Tomé do Nascimento Filho

ORCID: https://orcid.org/0000-0002-1693-1008 Instituto Federal de Educação, Ciência e Tecnologia do Ceará, Brasil E-mail: vicentetnf@hotmail.com

\begin{abstract}
Resumo
Com a descoberta do novo coronavírus em 2019, na china o mundo se viu diante da disseminação de notícias falsas, as fake news, que levaram várias informações erradas e desinformando a população em relação à COVID-19, e o seu tratamento. Procurou-se neste artigo fazer uma correlação ou trazer a baila uma discussão sobre a disseminação das notícias falsas e a Alfabetização Científica e Tecnológica da população, procurando tratar do tema como uma forma de diminuir a credibilidade dessas notícias não verdadeiras, a partir do cidadão alfabetizado científica e tecnologicamente, dando a este o discernimento para que possa procurar fontes seguras para confirmar ou até refutar informações baseadas em fontes seguras. Imaginando-se que a ACT, possa propiciar à pessoa forma de resolver $\mathrm{e}$ participar das resoluções de problemas ocasionadas pela ciência e pela tecnologia, pois, o mesmo saberá procurar fontes seguras para embasar sua resposta ao problema, e a noticia falsa surge como uma problemática que necessita de resolução. Neste artigo procurou-se também fazer um relato sobre os temas abordados e para isto foi realizado uma revisão integrativa da literatura com foco principal na relação da formação cidadã.
\end{abstract}

Palavras-chave: Covid -19; Alfabetização científica e tecnológica; Fake News.

\begin{abstract}
With the discovery of the new coronavirus in 2019 , in china the world was faced with the dissemination of false news, as fake news, which led to various misinformation and misinformation of the population in relation to COVID-19 and its treatment. this article sought to make a correlation or bring up a discussion about the dissemination of false news and the Scientific and Technological Literacy of the population, seeking to address the issue as a way to reduce the credibility of these untrue news, from the literate citizen. scientifically and technologically, giving it the insight so that it can look for reliable sources to confirm or even refute information based on reliable sources. imagining that the ACT, I can provide the person with a way to solve and participate in the resolution of problems caused by science and technology, because he will know how to pricire reliable sources to support his response to the problem, and false news emerges as a problematic that needs resolution. In this article, an attempt was also made to report on the topics covered, and for this, an integrative literature review was carried out with the main focus on the relationship of citizen education.
\end{abstract}

Keywords: Covid-19; Scientific and technological literacy; Fake news.

\section{Resumen}

Con el descubrimiento del nuevo coronavirus en 2019, en China el mundo se enfrentó a la difusión de noticias falsas, como fake news, lo que generó diversa desinformación y desinformación de la población en relación al COVID-19 y su tratamiento. Este artículo buscó hacer una correlación o plantear una discusión sobre la difusión de noticias falsas y la Alfabetización Científica y Tecnológica de la población, buscando abordar el tema como una forma de restar 
credibilidad a estas noticias falsas, desde el ciudadano alfabetizado. científica y tecnológicamente, dándole la información necesaria para que pueda buscar fuentes confiables para confirmar o incluso refutar información basada en fuentes confiables. imaginando que el ACT, puedo brindarle a la persona una forma de resolver y participar en la resolución de los problemas ocasionados por la ciencia y la tecnología, porque sabrá cómo buscar fuentes confiables para sustentar su respuesta al problema, y las noticias falsas surgen como una problemática que necesita resolución. En este artículo también se intentó informar sobre los temas tratados, y para ello se realizó una revisión integradora de la literatura con el foco principal en la relación de la educación ciudadana.

Palabras clave: Covid-19; Alfabetización científica y tecnológica; Noticias falsas.

\section{Introdução}

Em dezembro de 2019 o mundo foi abalado com a notícia de que era identificado na China, mais especificamente em Wuhan, província de Hubei, um novo vírus que contaminou pessoa em um mercado de frutos do mar e de animais vivos, este vírus foi chamado provisoriamente de 2019-nCov, e depois receberia o nome de Severe Acute Respiratory Syndrome Coronavirus 2 (SARS-COV-2) e sua doença seria conhecida por COVID-19. (Guan, et al, 2020)

Com o relato do surgimento do COVID-19, iniciaram-se também a disseminação de outro tipo de notícias, as falsas (Fake News). As Fake News são disseminadas em vários formatos, de forma geral vem em um texto afirmativo, que levam as pessoas, por falta de informação a acreditarem nas notícias e até compartilhar as notícias falsas. As fakes News sobre o novo coronavírus levam medo e desinformação a população, o que atrapalha os órgãos oficiais no enfrentamento a esta doença grave. (Sousa Júnior, et al, 2020).

Acredita-se que uma forma de diminuir a disseminação de notícias falsas seja a Alfabetização Científica e Tecnológica da população. A Alfabetização Cientifica e Tecnológica é a compreensão básica que uma pessoa apresenta em ciência e tecnologia. São os conhecimentos básicos que uma pessoa tem que apresentar para como cidadão, poder opinar em assuntos sobre tecnologia e ciências, isso requer um cidadão que possa ler, compreender e expressar seu entendimento sobre assuntos de ordem científica e tecnológica. (Niezer, 2012).

Este artigo tem como objetivo discutir à importância da Alfabetização Científica e Tecnológica (ACT), diante ao grave problema de saúde pública, que é a pandemia pelo Novo Coronavírus, que assola não só o Brasil mais todo o mundo, e a divulgação das famosas Fake News que são disseminadas todos os dias pelas redes sociais.

Parte-se então para o desenvolvimento deste artigo do seguinte questionamento: A Alfabetização Científica e Tecnológica da população em geral, poderia ajudar a diminuir a crença em notícias falsas relacionadas a assuntos sobre ciências, especificamente sobre o Novo Coronavírus, e por consequência diminuir sua disseminação entre a população?

Para responder este questionamento, aborda-se neste artigo os principais conceitos sobre Alfabetização Científica e Tecnológica (ACT), informações sobre o Novo Coronavírus e também trataremos um pouco sobre o conceito de Fake News.

\section{Metodologia}

Este artigo caracteriza-se, por um estudo exploratório, a partir de uma revisão bibliográfica, com base em uma análise qualitativa das publicações recentes sobre os temas em estudo. No caso da revisão bibliográfica e da análise qualitativa será em relação a Alfabetização Científica e Tecnológica (ACT), já a pesquisa exploratória será sobre o Novo Coronavírus e sobre as notícias falsas.

Para Gil (2008) os estudos exploratórios são realizados com o intuito de proporcionar uma visão geral e aproximativa de um determinado fato, e que se escolhe este tipo de estudo quando o tema é pouco explorado tornando-se difícil a formulação de hipóteses com exatidão que sejam operacionáveis. 
Com foco na ACT, os dados serão analisados e discutidos sobre a égide de uma abordagem metodológica qualitativa, com o intuito de elencar os pontos de vistas dos teóricos sobre o tema. Nas palavras de Freitas e Pandonov (2013) a pesquisa qualitativa:

Considera que há uma relação dinâmica entre o mundo real e o sujeito, isto é, um vínculo indissociável entre o mundo objetivo e a subjetividade do sujeito que não pode ser traduzido em números. A interpretação dos fenômenos e a atribuição de significados são básicas no processo de pesquisa qualitativa. Esta não requer o uso de métodos e técnicas estatísticas. O ambiente natural é a fonte direta para coleta de dados e o pesquisador é o instrumento-chave. Tal pesquisa é descritiva. Os pesquisadores tendem a analisar seus dados indutivamente. O processo e seu significado são os focos principais de abordagem (Freitas; Pandonov, 2013, p. 70).

Para dar embasamento ao estudo qualitativo da ACT, optou-se por fazer uma pesquisa bibliográfica sobre o tema. Para Lakatos e Marcone (2003) a pesquisa bibliográfica é dividida em oito etapas distintas: escolha do tema, elaboração do plano de trabalho, identificação, localização, compilação, fichamento, análise e interpretação, e por último a redação.

A pesquisa bibliográfica objetiva, pôr o pesquisador em conexão direta com o material já escrito sobre o assunto estudado. É realizada com material já publicado composto basicamente por artigos científicos, livros, monografias, dissertações e teses (Freitas; Pandonov, 2013).

Para a realização desta pesquisa bibliográfica usou-se como base de dados o Google Acadêmico, Periódicos CAPES e o Scielo. Procurou-se publicações ocorridas do ano de 2015 a junho de 2020, em português e que tivesse como tema central a Alfabetização Científica e Tecnológica.

\section{Resultados e Discussão}

Antes de iniciarmos a discutir os resultados, vamos fazer um preambulo sobre dois temas que são indispensáveis ao entendimento dos resultados obtidos. Vamos tratar sobre o COVID-19 e as Fake News, após está introdução iniciaremos os resultados e a discussão dos resultados obtidos.

\subsection{Pandemia da COVID-19}

Os coronavírus já são amplamente distribuídos entre os humanos, outros mamíferos e aves. Os coronavírus são vírus RNA, que quando observados com o uso da microscopia eletrônica tem a forma de círculo, com espículas ${ }^{1}$ que terminam em gotículas dando uma forma de coroa (Figura 1), daí a origem do nome corona (que em latim quer dizer coroa). Até 2019 conheciam-se seis diferentes cepas de coronavírus que causavam doenças em seres humanos, dentre essas seis cepas quatro delas (229E, NL63, OC43 e o HKU1) de alta prevalência e associadas a quadro de resfriados e infecções leves, as duas outras cepas tem origem zoonótica, a severe acute respiratory syndrome coronavírus (SARS-CoV) e a middle east reapiratory syndrome coronavírus (MERS-CoV), e estão associadas a insuficiências respiratória graves e potencialmente fatais (Guan, et al, 2020; Zhu, et al, 2020). 
Figura 1: Imagem de microscopia eletrônica do novo coronavírus.

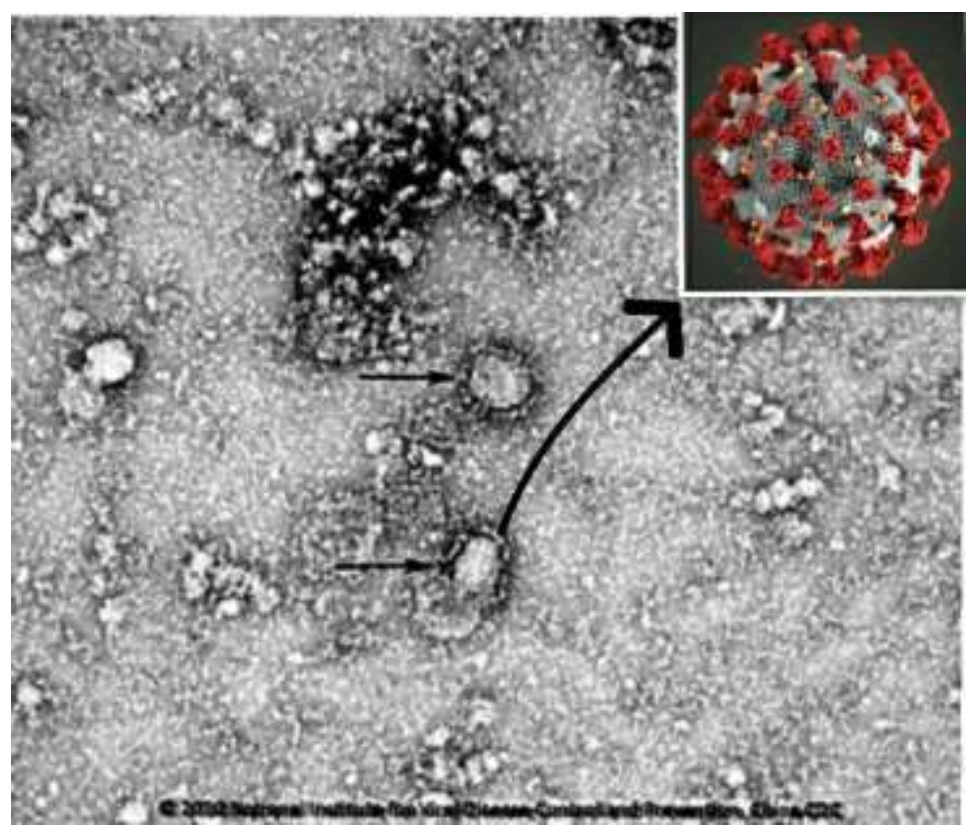

Fonte: Sociedade Brasileira de pediatria: Documento científico, (2020, p. 2)

Em estudos anteriores, forma identificados a presença de coronavírus em animais como: camundongos, ratos, galinhas, perus, suínos, cães, gatos, coelhos, cavalos gados e humanos, e alertavam que esse tipo de vírus poderia causar vários tipos de doenças graves como gastroenterites e doenças no trato respiratório (Sousa Júnior, et al, 2020).

Em 31 de dezembro de 2019, surgiu em Wuhan uma nova cepa do coronavírus, o sétimo desta família, capaz de infectar humanos. Este novo coronavírus recebeu o nome de SARS-CoV-2 e causa a doença conhecida como COVID-19, que possui uma taxa de contagio superior as seis primeiras cepas, que fez com que a Organização Mundial de Saúde (OMS) dois meses após a descoberta desta cepa, dia 13 de março de 2020, decretar o status de pandemia, que ocorre quando há casos de infecção em todos os continentes (Zhu, et al, 2020).

O nome SARS-CoV-2, foi dado ao novo coronavírus, por se tratar de uma síndrome respiratória aguda grave que tem origem na interação entre humanos e animais selvagens, principalmente pela cultura de usar esses animeis como alimento (Chaves; Belei, 2020).

As primeiras informações sobre o novo coronavírus relatam uma doença com alta taxa de contaminação, porém com baixa letalidade. As principais formas de transmissão do vírus são a direta (tosse, espirro), e contato com mucosa oral, nasal e dos olhos, além dessas formas, estudos apontam que o vírus poderia ser transmitido por contatos diretos ou indiretos com fluidos e saliva (Tuñas, et al, 2020)

Tabela 1: Vias de transmissão.

\begin{tabular}{c|c}
\hline Transmissão & Característica \\
\hline Direta & Através de tosse, espirros, gotículas da saliva e outra secreções corpóreas. \\
\hline Por contato & $\begin{array}{c}\text { Com a mucosa oral, nasal e ocular. Após tocar com as mãos em superfície contaminada e depois } \\
\text { tocar os olhos, nariz ou a boca. }\end{array}$ \\
\hline $\begin{array}{c}\text { Outros meios (procedimentos } \\
\text { odontológicos e fisioterapias respiratórias) }\end{array}$ & Aerossóis que contem sangue e saliva \\
\hline
\end{tabular}

Fonte: Elaborado pelos autores. 
Os sintomas da COVID-19 causada pelo novo coronavírus podem ser leves como febre, tosse, falta de ar ou a doença pode evoluir para sintomas mais graves como pneumonia e dificuldade de respirar. O período de incubação do vírus e de aproximada 5 dias. (Sousa Júnior, et al, 2020; Tuñas, et al, 2020)

Figura 2: Diagrama com características clínicas da doença COVID-19.

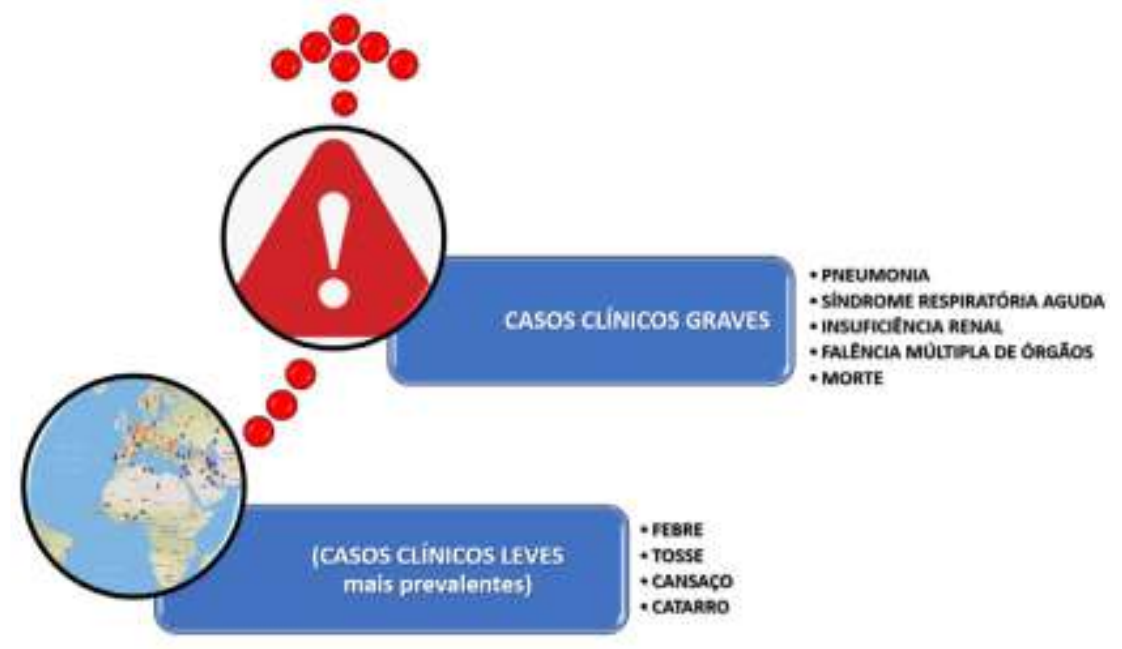

Fonte: Tuñas, et al (2020, p. 2).

Foram confirmados no mundo 263.563.622 novos casos e 5.232.562 mortes, na região das américas são 97.326.081 pessoas infectadas até 02 de dezembro de 2021 segundo informação no site da Organização Mundial de Saúde (OMS).

Em 26 de fevereiro de 2020, foi detectado o primeiro caso positivo de COVD-19 no Brasil, seria um paulista que tinha feito uma recente viagem à Itália, após cinco dias passados do primeiro caso teve-se a informação do segundo caso confirmado de COVID no pais, e chegando a 25 casos confirmado apenas 11 dias passados do primeiro teste positivo, e no dia 13 de março o brasil decreta quarentena por 15 dias. (Macedo et al., 2020)

No Brasil de acordo com site do Ministério da Saúde (MS) o total de casos confirmados é de 22.129.405 pessoas que tesaram positivo para a COVID-19, e 615.400 óbitos até o dia 03 de dezembro de 2021.

Mesmo com o avanço da vacinação no País, algumas precauções são importantes para se prevenir a infecção pelo COVID-19, lavar as mãos frequentemente com água e sabão ou na falta deste usar álcool gel 70, evitar tocar os olhos, nariz e boca com as mãos não lavadas, evitar contato com pessoas suspeitas de estarem com COVID ou que já tenham o diagnostico positivos, se doente ficar em casa, dentre outras medidas. (Sociedade Brasileira de Pediatria, 2020)

Diante do exposto aqui neste tópico, podemos perceber que a informação é umas das principais armas de enfrentamento ao novo coronavírus. Então fica evidente que quando surgem notícias falsas de como combate essa doença e um desserviço e uma forma de atrapalhar os agentes públicos na tentativa de tratamento e de informação da população sobre o COVID-19. (Alexandre 2020; Sousa Júnior, 2020)

\subsection{Fake News: Atrapalhando o combate ao COVID-19}

As Fake News, notícias falsas, traduzindo para o português, passaram a ser conhecidas mundialmente quando utilizadas no cenário político nas eleições presidenciais no Estados Unidos da América em 2016, quando Donald Trump foi eleito, mas as notícias falsas não ficam restrita apenas ao cenário político e sim a vários assuntos, sendo disseminadas nas redes sociais e interferindo nos mais diversos contextos sociais (Sousa Júnior, et al, 2020). 
Pode-se conceituar Fake News como a disseminação de notícias falsas por qualquer meio de comunicação com o objetivo de desinformar, de despertar o interesse para desinformação e conseguir com isso vantagens econômicas ou políticas (Braga 2018; Lins \& Lopes, 2018)

A disseminação de conteúdos falsos, que ocorre de forma descontrolada, geralmente é estruturada em um formato jornalístico, fornecendo assim uma certa confiabilidade à notícia. Transformando essa disseminação em massa de notícias falsas, em desinformação e um problema de saúde pública (Matos, 2020).

Mesmo os órgãos de governo tomando várias medidas para deixar a população informada sobre os protocolos utilizados para o tratamento e as formas de atenuar o contágio, essas medidas não foram suficientes para evitar a disseminação de notícias falsas e recuperar a confiança do público (Tapia, 2020).

Neto, et al, 2020 separa as notícias falsas em cinco categorias informações relacionadas aos discursos de autoridades na saúde; terapêutica; medida de prevenção; prognóstico de doenças e prevenção. O Quadro 1 apresenta alguns exemplos de notícias falsas que são mostradas no site do MS.

Quadro 1. Exemplos de Fake News (banco de dados do Ministério da Saúde).

\begin{tabular}{|l|l|c|}
\hline Categoria & \multicolumn{1}{|c|}{ Título da noticia } & $\begin{array}{c}\text { Veículo de } \\
\text { informação }\end{array}$ \\
\hline $\begin{array}{l}\text { Informações relacionadas aos discursos de } \\
\text { autoridades na saúde }\end{array}$ & $\begin{array}{l}\text { Aplicativo Coronavírus-SUS, do Governo } \\
\text { do Brasil, é inseguro }\end{array}$ & WhatsApp \\
\hline Terapêutica & $\begin{array}{l}\text { Tomar bebidas quentes para matar o } \\
\text { coronavírus }\end{array}$ & WhatsApp \\
\hline Medidas de prevenção & $\begin{array}{l}\text { Beber muita água e fazer gargarejo com } \\
\text { água morna, sal e vinagre previne } \\
\text { coronavírus }\end{array}$ & WhatsApp \\
\hline Prognósticos de doenças & $\begin{array}{l}\text { Pesquisa aplicada por cientistas chineses } \\
\text { diz que coronavírus tornará a maioria dos } \\
\text { pacientes do sexo masculino infértil. }\end{array}$ & Internet \\
\hline Vacinação & China anuncia vacina para o coronavírus & Internet \\
\hline
\end{tabular}

Fonte: Adaptada pelo autor de Neto, et al, 2020, p. 3.

Diante do exposto percebe-se o quanto rápido e destruidor é a disseminação das Fake News, passando-se a questionar evidencias científicas baseadas em estudos, e se levar em consideração simplesmente qualquer notícia que trazia a resposta que se queria ver. Isso mostra que Alfabetizar Científica e Tecnologicamente a população é muito importante, pois nas palavras de Niezer (2012), alfabetizar em ciências e tecnologia uma pessoa e dar a ela a possibilidade de questionar e participar de debates em que o tema é a ciência e a tecnologia, é dar a possibilidade do cidadão de perceber ou pelo menos ter a iniciativa de procurar fontes fidedignas para atestar se a notícia que ele está lendo é verdadeira ou não passa de uma Fake News.

\subsection{Alfabetização Científica e Tecnológica}

Trata-se aqui neste tópico o conceito de Alfabetização Científica e Tecnológica (ACT), e seu papel na formação do cidadão consciente de seus direitos e de seus deveres, e com discernimento para tratar sobre assuntos científicos.

A definição de alfabetização surge nos séculos XIX e XX, objetivando ensinar as pessoas a ler e escrever, para que pudessem ter ascensão tanto social como cultural, o desenvolvimento científico tecnológico do século XX, trouxe novas necessidade para as pessoas do século XXI, que estão rodeadas de tecnologias e ciência, e uma dessas necessidades foi a Alfabetização Científica e Tecnológica (Firme \& Miranda, 2020)

O termo Alfabetização Científica e Tecnológica foi usado pela primeira vez segundo Sasseron e Carvalho (2011) por Paul Hurd em seu livro "Science Literacy: Its Meaning for American Schools”, publicado em 1958. Neste artigo empregarmos termo Alfabetização Científica e Tecnológica. 
A ACT, via de regra, debate a necessidade de o cidadão ter o mínimo de conhecimento científico, para então, desempenhar seu papel como cidadão e discernir sobre seus direitos diante a uma sociedade moderna, partindo-se da premissa de que o conhecimento científico deva estar profundamente ligado ao progresso da sociedade e da tecnologia (Niezer, 2012; Rosa; Lorenzetti; Lambach, 2019).

[...] é o objetivo da Alfabetização Científica, capacitar os estudantes a compreenderem os fenômenos científicos, suas relações ecológicas, sociais e ambientais, de forma a tornarem-se mais ativos e críticos diante de situações relacionadas à ciência e tecnologia. Assim poderão estar preparados para compreender o mundo natural, relacionando experiências do cotidiano, podendo nelas interferir com competência, por meio de envolvimento e interpretação do conhecimento científico. (Costa; Lorenzetti, 2020, p. 14)

A ACT, abrange o entendimento dos conceitos científicos e sua associação a contextos. As pessoas devem ser capazes de refletir sobre ciência e de observar suas mudanças, e reconhecer as várias aplicações desses conhecimentos em sua vida cotidiana, com isso podem preparar-se para participar dos processos democráticos da sociedade (Costa; Lorenzetti, 2020)

Sasseron e Carvalho (2011), Rosa, Lorenzetti e Lambach (2019) e Costa e Lorenzetti (2020) trazem a categorização da ACT feita por Bybee (1997), estas categorias são utilizadas para determinar o grau e a dimensão da Alfabetização Científica.

Com visão na aprendizagem do conhecimento científico Bybee (1997) que divide a AC em quatro classes (Quadro 2): nominal, funcional, conceitual e processual e multidimensional, essas categorias podem ajudar na elaboração de um de verificação do grau de AC tanto para o professor quanto para o aluno.

Quadro 2: Classificação da Alfabetização Científica e Tecnológica segundo Bybee (1997)

\begin{tabular}{|c|l|}
\hline Classe & \multicolumn{1}{c|}{ Descrição } \\
\hline ACT nominal & $\begin{array}{l}\text { Os indivíduos tem relação com os nomes, isso quer dizer que alguém nominalmente } \\
\text { alfabetizado na ciência, consegue perceber que o tema abordado tem relação com } \\
\text { ciência, porém não saberá mais nada além disso. }\end{array}$ \\
\hline ACT funcional & $\begin{array}{l}\text { Tem o objetivo de desenvolver conceitos, concentrando-se na aquisição de um } \\
\text { vocabulário e termos técnicos que envolvam ciência e tecnologia }\end{array}$ \\
\hline $\begin{array}{c}\text { ACT conceitual e } \\
\text { processual }\end{array}$ & $\begin{array}{l}\text { Os indivíduos já conseguem dar seus próprios significados aos conceitos científicos e } \\
\text { relacionando a informações e fatos no contexto da ciência e tecnologia }\end{array}$ \\
\hline $\begin{array}{c}\text { ACT } \\
\text { multidimensional }\end{array}$ & $\begin{array}{l}\text { Os indivíduos são capazes de se apropriar dos conhecimentos e explica-los, além de } \\
\text { conseguir empregar na resolução de problemas do seu dia-a-dia. }\end{array}$ \\
\hline
\end{tabular}

Fonte: Adaptado pelo autor de Rosa, Lorenzetti e Lambach (2019).

Costa e Lorenzetti (2020) trazem também em seu artigo intitulado "A promoção da alfabetização científica nos anos finais do ensino fundamental por meio de uma sequência didática sobre crustáceos” a classificação de Shen (1975), que tem o objetivo de mostrar que a Alfabetização Científica deve proporcionar um conhecimento técnico e científico de imediato uso, e que possa ajudar a melhorar os padrões de vida (Costa; Lorenzetti, 2020). Shen (1975 divide a AC em três classes a Alfabetização Científica prática, a Alfabetização Cientifica cívica e a Alfabetização Científica Cultural, descritas no Quadro 3. 
Quadro 3: Classificação da Alfabetização Científica segundo Shen (1975).

\begin{tabular}{|c|l|}
\hline Classe & \multicolumn{1}{|c|}{ Descrição } \\
\hline AC prática & $\begin{array}{l}\text { Determina a posse do conhecimento científico que poderá ser usado para resolução de } \\
\text { problemas, esse conhecimento científico e técnico pode ser posto imediatamente em } \\
\text { prática para melhorar os padrões de vida do indivíduo. }\end{array}$ \\
\hline AC cívica & $\begin{array}{l}\text { Torna cidadão mais atento aos problemas da ciência, proporcionando a ele a capacidade } \\
\text { de tomar decisões. Este e capacitado a tornar-se mais informado sobre a ciência e as } \\
\text { questões relacionadas a ela. }\end{array}$ \\
\hline AC Cultural & $\begin{array}{l}\text { Motivado pelo desejo do saber, saber mais sobre ciências. Não resolve nenhum problema } \\
\text { prático diretamente, mas ajuda a abrir caminhos e contribui para a expansão do } \\
\text { conhecimento científico dos indivíduos podendo lhe dar autonomia intelectual, } \\
\text { estimulando-os a quererem aprender mais sobre determinados assuntos }\end{array}$ \\
\hline
\end{tabular}

Fonte: Adaptado pelo autor de Costa e Lorenzetti (2020).

Vale ressaltar que o foco deste artigo é procurar dimensionar a ACT em relação aos conhecimentos científicos e tecnológicos, que traz à tona a difícil relação entre ciência, tecnologia e sociedade, e a possível diminuição das notícias falsas ou fake news.

E assim se assume que a ACT é imprescindível para a sociedade atual e como objetivo primordial do ensino de ciências (Firme \& Miranda, 2020)

\subsection{Resultados e discussões}

Este tópico apresentará resultados e discussão da pesquisa bibliográfica realizada sobre a Alfabetização Científica e Tecnológica para dar respaldo teórico a pesquisa sobre a relação entre a ACT e a disseminação de Fake News.

Para a realização da pesquisa bibliográfica usou-se com base de dados o Google Acadêmico, Periódicos CAPES e Scielo, como descrito anteriormente na metodologia. Considerando o primeiro critério de inclusão que é ter no título o termo Alfabetização Científica e Tecnológica e o segundo que é ter sido publicado no período de 2015 a junho de 2020 chegou-se a um total de 168 (cento e sessenta e oito) artigos, sendo 34 (trinta e quatro) artigos encontrados no Google Acadêmico, 102 (cento e dois) no Periódicos CAPES e 32 (trinta e dois) na base de dados Scielo. Destes, foram, por triagem de relevância com o estudo aqui realizado, e pela pesquisa tratar somente da ACT e não associado a outro tema, escolhido 30 (trinta) artigos. Contudo como o foco principal do estudo é a formação do cidadão a partir da ACT, chegou-se a 9 (nove) artigos para a realização do estudo bibliográfico. 
Research, Society and Development, v. 11, n. 1, e17911124339, 2022

(CC BY 4.0) | ISSN 2525-3409 | DOI: http://dx.doi.org/10.33448/rsd-v11i1.24339

Figura 3: Diagrama das etapas de escolha dos artigos para a realização do estudo.

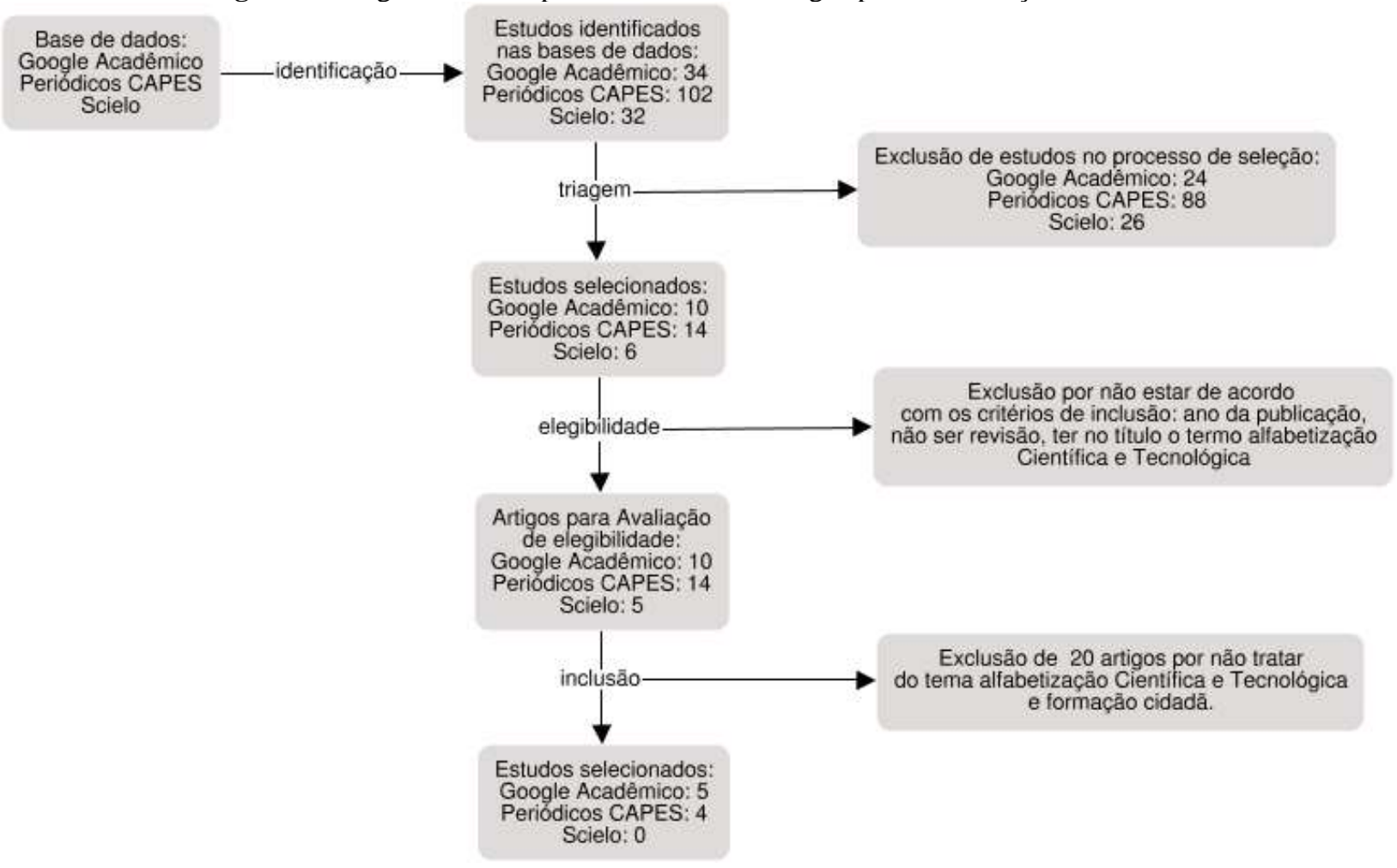

Fonte: Elaborado pelos autores.

O Quadro 4 organiza os critérios de inclusão e exclusão que foram definidos e usados para a seleção dos artigos a serem utilizados na revisão bibliográfica neste artigo.

Quadro 4: Critérios de inclusão e exclusão.

\begin{tabular}{|l|l|}
\hline \multicolumn{1}{|c|}{ Inclusão } & \multicolumn{1}{c|}{ Exclusão } \\
\hline Estudos relacionando a ACT e a formação cidadã. & Estudos publicados em língua diferente da portuguesa. \\
\hline Estudos publicados entre 2015 e junho de 2020. & Estudos duplicados. \\
\hline Estudos acessíveis de forma gratuita via web. & Estudos publicados anteriormente a 2015. \\
\hline Estudos em língua portuguesa. & Estudos duplicados do mesmo autor \\
\hline Ser artigo científico & Ser dissertação ou tese ou TCC \\
\hline
\end{tabular}

Fonte: Elaborado pelos autores.

Como fica evidente na Figura 5, foram selecionados um total de 29 artigos científicos e em uma primeira verificação percebeu-se a distribuição deles de forma não linear durantes os anos de publicação, observou-se que nos anos de 2017,2019 e 2020 teve-se uma frequência maior de publicações sobre o tema, já nos anos de 2015, 2016 e 2018, houve uma diminuição de publicações sobre o assunto ACT, no Gráfico 1 pode-se perceber bem esta distribuição. 
Research, Society and Development, v. 11, n. 1, e17911124339, 2022

(CC BY 4.0) | ISSN 2525-3409 | DOI: http://dx.doi.org/10.33448/rsd-v11i1.24339

Figura 4: Gráfico de tendência de publicações.

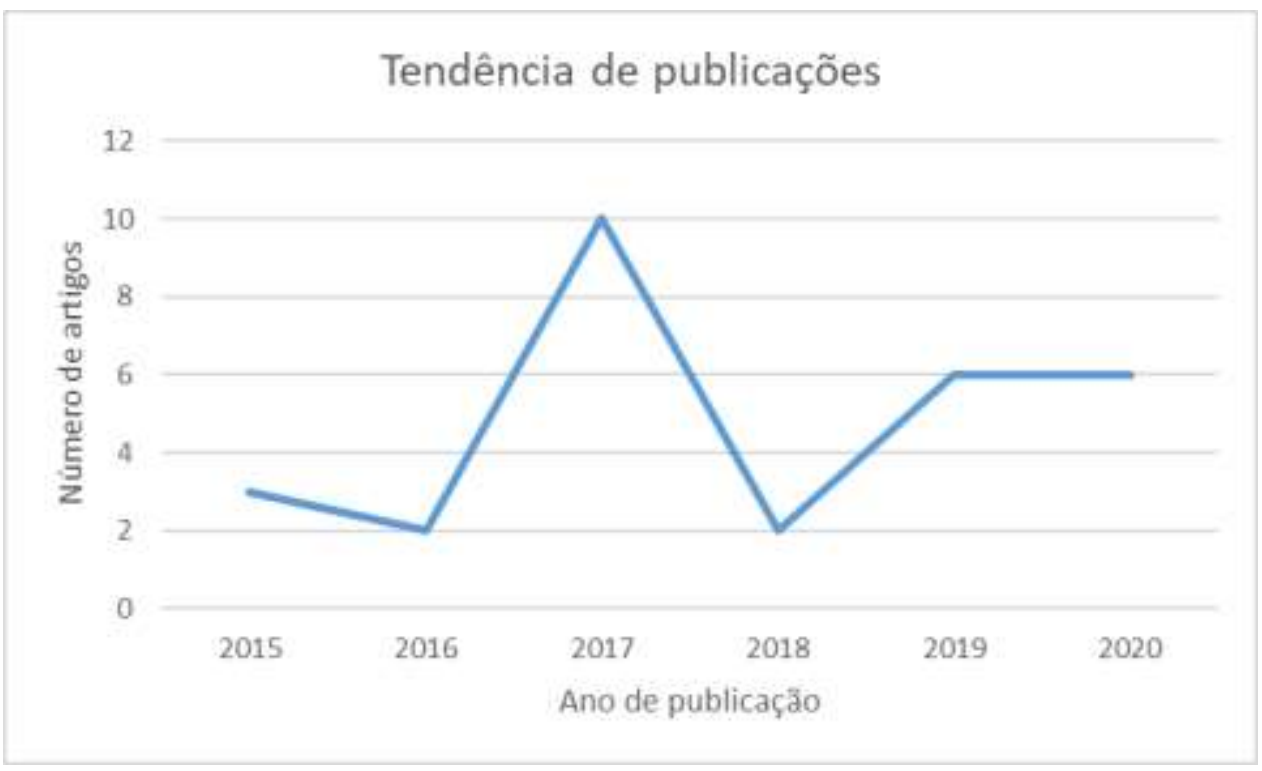

Fonte: Elaborado pelos autores.

Os 29 estudos selecionados estão organizados na tabela $n$, onde poderemos verificar algumas informações iniciais sobre eles como título, periódico ano de publicação e autores, estes artigos receberão um código próprio para identificação, para facilitar na hora das discussões sobre os mesmos.

Quadro 5: Artigos selecionados para o estudo.

\begin{tabular}{|c|c|c|c|c|c|}
\hline Código & $\begin{array}{c}\text { Ano } \\
\text { Publicação }\end{array}$ & Título & Autor (es) & Periódico & Qualis* \\
\hline A001 & 2015 & $\begin{array}{l}\text { Promovendo a Alfabetização Científica } \\
\text { por meio de Ensino Investigativo no } \\
\text { Ensino Médio de Química: } \\
\text { Contribuições para a Formação Inicial } \\
\text { Docente } \\
\text {. }\end{array}$ & $\begin{array}{l}\text { MIRANDA, M. S.; SUAR, R. C.; } \\
\text { MARCONDES, M. E. R. }\end{array}$ & $\begin{array}{l}\text { Revista Ensaio: Pesquisa } \\
\text { em Educação em Ciência }\end{array}$ & $\mathrm{A} 2$ \\
\hline A002 & 2015 & $\begin{array}{l}\text { Alfabetização Científica, ensino por } \\
\text { Investigação e Argumentação: Relações } \\
\text { entre ciências da naturza e Escola }\end{array}$ & SASSERON, L.H. & $\begin{array}{l}\text { Revista Ensaio: Pesquisa } \\
\text { em Educação em Ciência }\end{array}$ & $\mathrm{A} 2$ \\
\hline A003 & 2015 & $\begin{array}{c}\text { A concepção de Educação para Álvaro } \\
\text { Vieira Pinto e sua Contribuição para } \\
\text { Repensar Estudos sobre um Ensino } \\
\text { Tecnológico Humanizador }\end{array}$ & $\begin{array}{l}\text { HERCULANO, V. C.; FERREIRA, } \\
\text { L. C }\end{array}$ & Revista Educitec & B1 \\
\hline A004 & 2016 & $\begin{array}{c}\text { Alfabetização Científica e Tecnológica } \\
\text { na Formação do Cidadão }\end{array}$ & $\begin{array}{c}\text { MARCHESAN, M. R.; KUHN, M. } \\
\text { C. }\end{array}$ & Revista THEMA & B2 \\
\hline A005 & 2016 & $\begin{array}{l}\text { O Estudo de Temas Tecnológicos na } \\
\text { Educação CTSA: Uma Experiência de } \\
\text { Alfabetização Científica e Tecnológica } \\
\text { no Ensino Médio }\end{array}$ & $\begin{array}{l}\text { RIBEIRO, T. V.; COLHERINHAS, } \\
\text { G.; GENOVESE, L. G. R. }\end{array}$ & REnCiMa & $\mathrm{A} 2$ \\
\hline A006 & 2017 & $\begin{array}{c}\text { Alfabetização Científica ou Letramento } \\
\text { Científico: Interesses envolvidos nas } \\
\text { interpretações da noção de scientific } \\
\text { literacy. }\end{array}$ & CUNHA, R. B. & $\begin{array}{l}\text { Revista Brasileira de } \\
\text { Educação }\end{array}$ & A1 \\
\hline A007 & 2017 & $\begin{array}{l}\text { Indicadores de Alfabetização Científica: } \\
\text { um estudo em espaços não formais da } \\
\text { cidade de Toledo, PR }\end{array}$ & $\begin{array}{l}\text { FERREIRA, M.; AVES, G. L.; } \\
\text { CUNHA, M. B.; LEITE, R. F. }\end{array}$ & $\begin{array}{l}\text { ACTIO: Docência em } \\
\text { Ciências }\end{array}$ & B2 \\
\hline A008 & 2017 & $\begin{array}{c}\text { Alfabetização Científica e Tecnológica } \\
\text { na formação do cidadão }\end{array}$ & $\begin{array}{l}\text { DUTRA, G. E.; OLIVEIRA, E. C.; } \\
\text { DEL PINO, J. C }\end{array}$ & Revista SIGNOS & B3 \\
\hline A009 & 2017 & $\begin{array}{l}\text { Alfabetização Científica e Tecnológica } \\
\text { como possibilidade de formação do } \\
\text { cidadão a partir de uma abordagem da } \\
\text { educacão em saúde }\end{array}$ & $\begin{array}{l}\text { MONTEIRO, S.; PISSAIA, L. F.; } \\
\text { LORENZON, M.; OLIVEIRA, E. } \\
\text { C.; DEL PINO, J. C. }\end{array}$ & Caderno Pedagógico & B3 \\
\hline A010 & 2017 & $\begin{array}{l}\text { A compreensão dos professores sobre } \\
\text { alfabetização Científica: perspectivas e } \\
\text { realidade para o Ensino de Ciências. }\end{array}$ & $\begin{array}{c}\text { OLDONI, J. F. W. B.; LIMA, B. G. } \\
\text { T. }\end{array}$ & $\begin{array}{l}\text { ACTIO: Docência em } \\
\text { Ciências }\end{array}$ & B2 \\
\hline
\end{tabular}


Research, Society and Development, v. 11, n. 1, e17911124339, 2022

(CC BY 4.0) | ISSN 2525-3409 | DOI: http://dx.doi.org/10.33448/rsd-v11i1.24339

\begin{tabular}{|c|c|c|c|c|c|}
\hline A011 & 2017 & $\begin{array}{c}\text { O enfoque Ciência, Tecnologia e } \\
\text { Sociedade como promoção da } \\
\text { Alfabetização Científica e Tecnológica } \\
\text { em museus de ciências. } \\
\end{array}$ & $\begin{array}{l}\text { PALMIERI, L. J.; SILVA, C. S.; } \\
\text { LORENZETT, L.I }\end{array}$ & $\begin{array}{l}\text { ACTIO: Docência em } \\
\text { Ciências }\end{array}$ & B2 \\
\hline A012 & 2017 & $\begin{array}{c}\text { Parâmetros de alfabetização Científica e } \\
\text { Alfabetização Tecnológica na Educação } \\
\text { em Química: analisando a temática } \\
\text { ácidos e bases. }\end{array}$ & $\begin{array}{c}\text { LORENZETTI, L.; SIEMSEN, G. } \\
\text { H.; OLIVEIRA, S. }\end{array}$ & $\begin{array}{l}\text { ACTIO: Docência em } \\
\text { Ciências }\end{array}$ & B2 \\
\hline A013 & 2017 & $\begin{array}{c}\text { Potencialidades do filme de ficção } \\
\text { Avatar para a alfabetização Científica } \\
\text { dos sujeitos no contexto da educação } \\
\text { básica. }\end{array}$ & SANTOS, W. J.; SILVA, I. P. & $\begin{array}{l}\text { Amazonas: Revista de } \\
\text { Educação em Ciência e } \\
\text { matemática }\end{array}$ & A2 \\
\hline A014 & 2017 & $\begin{array}{l}\text { A escola como ambiente de formação } \\
\text { cidadã: uma abordagem a partir da } \\
\text { alfabetização Científica e Tecnológica. }\end{array}$ & $\begin{array}{c}\text { PISSAIA, L, F.; OLIVEIRA, E. C.; } \\
\text { DEL PINO, J. C }\end{array}$ & $\begin{array}{l}\text { Researsh, Soiety and } \\
\text { Development }\end{array}$ & B2 \\
\hline A015 & 2017 & $\begin{array}{l}\text { Alfabetização Científica e Tecnológica: } \\
\text { uma necessidade à formação docente. }\end{array}$ & $\begin{array}{l}\text { TORRES, I. C.; SILVA, J. L.; } \\
\text { ALVES, F. M. D. }\end{array}$ & Revista Educitec & B1 \\
\hline A016 & 2018 & $\begin{array}{l}\text { O processo de reflexão orientada na } \\
\text { formação inicial de um licenciando de } \\
\text { 0Química visando o ensino por } \\
\text { investigação e a promoção da } \\
\text { alfabetização Científica. }\end{array}$ & $\begin{array}{l}\text { SUART, R. C.; MARCONDES, M. } \\
\text { E. R. }\end{array}$ & $\begin{array}{l}\text { Revista Ensaio: Pesquisa } \\
\text { em Educação em Ciência }\end{array}$ & A2 \\
\hline A017 & 2018 & $\begin{array}{c}\text { Produção científica dos líderes de } \\
\text { grupos de pesquisa em Educação } \\
\text { Científica no Brasil: leitura da influência } \\
\text { na Alfabetização científica e no } \\
\text { desenvolvimento da cultura científica. }\end{array}$ & $\begin{array}{l}\text { CANTORANI, J. R. H.; } \\
\text { PEDROSO, B. }\end{array}$ & $\begin{array}{l}\text { Horizontes - Revista de } \\
\text { Educação }\end{array}$ & $\mathrm{B} 2$ \\
\hline A018 & 2019 & $\begin{array}{l}\text { Alfabetização Científico-Tecnológica } \\
\text { por meio de letras de músicas: } \\
\text { entendendo visões de ciência de Thomaz } \\
\text { Kuhn e Paul Feyerabend nas metáforas } \\
\text { de Raul Seixas }\end{array}$ & $\begin{array}{l}\text { MELO, M. G. A.; NEVES, M. C. } \\
\text { D.; SILVA, S. C. R. }\end{array}$ & Revista THEMA & B2 \\
\hline A019 & 2019 & $\begin{array}{l}\text { Níveis de Alfabetização Científica e } \\
\text { Tecnológica na avaliação de química do } \\
\text { Exame Nacional do Ensino Médio. }\end{array}$ & $\begin{array}{l}\text { ROSA, T. F.; LORENZETTI, L.; } \\
\text { LAMBACH, M. }\end{array}$ & $\begin{array}{l}\text { Educação Química en } \\
\text { Punto de Vista. }\end{array}$ & $* *$ \\
\hline A020 & 2019 & $\begin{array}{l}\text { Compreensões de professores dos anos } \\
\text { iniciais sobre os objetivos do ensino de } \\
\text { ciências, da alfabetização Científica e } \\
\text { Tecnológica e das relaçôes entre CTS no } \\
\text { ensino fundamental. }\end{array}$ & $\begin{array}{l}\text { BONFIM, H. C. C.; GUIMARÃES, } \\
\text { O. M. }\end{array}$ & $\begin{array}{l}\text { ACTIO: Docência em } \\
\text { Ciências }\end{array}$ & B2 \\
\hline A021 & 2019 & $\begin{array}{l}\text { Alfabetização Científica e Tecnológica } \\
\text { como princípio da formação do cidadão. }\end{array}$ & $\begin{array}{l}\text { FUMEIRO, C. L.; SILVEIRA, S. S. } \\
\text { S.; MARTINS, S. N.; SILVA, V. J. } \\
\text { M. O. }\end{array}$ & Revista Educitec & B1 \\
\hline A022 & 2019 & $\begin{array}{l}\text { Alfabetização Científica e Tecnológica - } \\
\text { ACT na formação acadêmica superior }\end{array}$ & $\begin{array}{c}\text { TRAPP, E. H. H.; } \\
\text { STROHSCHOEN, A. A. G.; } \\
\text { OLIVEIRA, E. C.; DEL PINO, J. } \\
\text { C. }\end{array}$ & $\begin{array}{c}\text { Revista Educação } \\
\text { Psicologia e Interfaces. }\end{array}$ & B4 \\
\hline A023 & 2019 & $\begin{array}{c}\text { Truques populares de limpeza } \\
\text { doméstica: potencialidades para a } \\
\text { alfabetização Científica e Tecnológica }\end{array}$ & SILVA, L. A. R.; MILARÉ, T. & Scientia Naturalis & $* *$ \\
\hline A024 & 2020 & $\begin{array}{c}\text { Um desafio para a Base Nacional } \\
\text { Comum Curricular: o diálogo entre a } \\
\text { Alfabetização Científica e Tecnológica e } \\
\text { a inclusão escolar. }\end{array}$ & RODRIGUES, P. A. A. & $\begin{array}{l}\text { Horizontes - Revista de } \\
\text { Educação }\end{array}$ & B2 \\
\hline A025 & 2020 & $\begin{array}{c}\text { Solução mineral milagrosa: um tema } \\
\text { para o ensino de Química na perspectiva } \\
\text { da Alfabetização Científica e } \\
\text { Tecnológica. }\end{array}$ & $\begin{array}{l}\text { MILARÉ, T.; RICHETTI, G. P.; } \\
\text { SILVA, L. A. R. }\end{array}$ & $\begin{array}{l}\text { Revista Ciência \& } \\
\text { Educação }\end{array}$ & $\mathrm{A} 1$ \\
\hline A026 & 2020 & $\begin{array}{l}\text { Impactos de um processo formativo na } \\
\text { alfabetização Científica e Tecnológica } \\
\text { de licenciandos em química. }\end{array}$ & FIRME, R. N.; MIRANDA, R. D. & Educación Química & A1 \\
\hline A027 & 2020 & $\begin{array}{c}\text { Alfabetização - uma evolução do } \\
\text { conceito: alfabetização e Letramento em } \\
\text { código. }\end{array}$ & $\begin{array}{l}\text { CORDENONZI; W. H.; DEL } \\
\text { PINO; J. C.; OLIVEIRA, E. C.; } \\
\text { STRANHSCHOEN, A. A. G. }\end{array}$ & $\begin{array}{c}\text { Testos Livres: } \\
\text { Linguagem e Tecnologia }\end{array}$ & $* *$ \\
\hline A028 & 2020 & $\begin{array}{c}\text { Possíveis confluências entre } \\
\text { Alfabetização Científica e ação } \\
\text { dialógica nos processos de formação do } \\
\text { sujeito }\end{array}$ & $\begin{array}{l}\text { LORENZON, M.; OLIVEIRA, E. } \\
\text { C.; DEL PINO, J. C. }\end{array}$ & Revista THEMA & B2 \\
\hline A029 & 2020 & $\begin{array}{c}\text { O uso do teste de Alfabetização } \\
\text { Científica básica no Brasil: uma revisão } \\
\text { da literatura. }\end{array}$ & $\begin{array}{l}\text { VIZZOTTO, P. A.; DEL PINO, J. } \\
\text { C. }\end{array}$ & $\begin{array}{l}\text { Revista Ensaio: Pesquisa } \\
\text { em Educação em Ciência }\end{array}$ & A2 \\
\hline
\end{tabular}

*QUALIS CAPES 2013-2016. ** periódicos sem classificação QUALIS. Fonte: Elaborado pelo autor 
Como o objetivo deste artigo é trazer a discussão sobre a formação de um cidadão consciente e que possa opinar sobre assuntos referentes a ciência e tecnologia e que este possa diferenciar ou pelo menos saber procurar fontes de pesquisa, para determinar se uma notícia é falsa ou não, sendo a ACT a base para essa formação.

Sendo assim dos 29 artigos apresentados no Quadro 5, selecionou-se os artigos A003, A004, A008, A009, A014, A018, A021, A023 e A028 que abordam a relação entre a ACT e a formação Cidadã.

Para subsidiar a discussão aqui sobre a temática da ACT e a formação cidadã iremos fazer uma análise breve sobre os oito artigos escolhidos, considerando-se o objetivo de cada artigo e as conclusões que os autores chegaram depois de seus estudos.

O artigo 003, apresentou dois objetivos o primeiro de contribuir com a Alfabetização Científica e Tecnológica a partir da visão de Álvaro Vieira Pinto, e de gerar uma reflexão sobre a possibilidade de conciliação entre ciência, existência e técnica. Os autores concluíram que de acordo com a concepção de Álvaro Vieira Pinto, a educação se trata de um bem de consumo cultural e coletivo e que pertence aos povos que necessitam de libertação e que a formação do cidadão cientificamente educado, está na capacidade de este cidadão de rever os valores éticos existencial da educação na sociedade (Herculano \&. Ferreira, 2015). Ainda para Herculano e Ferreira (2015, p. 11), "a sociedade educa os cidadãos e os cidadãos transformam a sociedade dialeticamente com os instrumentos pedagógicos que lhes são oferecidos".

O objetivo do artigo A004 e apresentar reflexões sobre a Alfabetização Científica e Tecnológica na formação do cidadão. Os autores deste estudo observaram um distanciamento entre as práticas educacionais e as transformações que ocorrem com a sociedade. Abordam o assunto considerando que existe uma supervalorização da ciência e da tecnologia em detrimento ao processo de ensino-aprendizagem e terminam seu estudo sugerindo que haja a formação de um cidadão que possa pensar, tomar decisões e propor alternativas e que principalmente seja capaz de enxergar os pontos positivos e negativos da ciência e da tecnologia (Marchesan \& Kuhn, 2016).

No estudo A008, os autores procuraram fazer uma relação entre a Alfabetização Científica e Tecnológica (ACT), com a formação do cidadão, discutindo os conceitos de ACT e tratando da formação inicial e continuada dos professores, pois segundo os autores estes tem um papel importante que lhe é exigido pela sociedade. Os autores consideram que o cidadão é alfabetizado cientificamente quando são capazes de autonomamente tomar decisões e terem posicionamento no mundo de hoje e que o professor tem que se apropriar dos conceitos científicos para que este possa levar aos alunos a possibilidade de se transformar neste cidadão (Dutra et al., 2017).

No artigo de Monteiro, et al (2017), artigo A009, o objetivo é compartilhar a vivência de uma professora nos anos iniciais no uso da Alfabetização Científica e Tecnológica (ACT) a partir de uma abordagem na educação em saúde no contexto escolar. E em suas considerações finais os autores mostram que a ACT tem sido fundamental na dinâmica da sociedade em relação ao desenvolvimento da ciência e tecnologia, e chegam a conclusão de que o ensino deve se utilizar da ACT para a formação do cidadão consciente de seus deveres e que possam tomar decisões acerca de assunto científico e tecnológicos (Monteiro, et al, 2017).

O estudo (A014) realizado por Pissaia et al. (2017), procurou compreender o papel da escola na formação do cidadão a partir de uma abordagem da Alfabetização Científica e Tecnológica. De acordo com os autores as reflexões partiram de um estudo da história e dos conceitos da ACT no contexto escolar, procurando compreender o amadurecimento do "ser" professor e aluno, neste importante processo de mudança. Observaram que movimentos envolvendo a ACT, associadas a outras habilidades reforçam o desenvolvimento do cidadão autossuficiente, tornando-o capaz de conceber seu conhecimento incorporado à suas necessidades comunitárias (Pissaia et al., 2017)

O estudo realizado por Melo et al., (2019), estudo classificado como A018, procurou fazer uma análise de partes de músicas com a Alfabetização Científica e Tecnológica, para os autores essa relação pode trazer para próximo doa alunos os 
conhecimentos sobre ciências e tecnologia, dando a oportunidades de esses alunos refletirem sobre as visões da ciência, e assim facilitar a formação de um cidadão, a escolha por este artigo ocorreu por tratar de sobre um assunto que está presente no dia a dia das pessoas. Segundo os autores a educação voltada a formação de um cidadão, não pode ser somente focada em conteúdos e de conceitos, mas sim também em conteúdos práticos e que as músicas são bons objetos de aprendizagem para este fim (Melo et al., 2019).

O artigo A021, tem como objetivo do estudo, refletir sobre a formação cidadã a partir da abordagem da ACT, e para conseguir chegar a este objetivo procurou realizar um estudo para compreender a ACT de forma mais ampla, e a relação da ACT com a educação básica que se torna um desafio já que é preciso que se possa superar o ensino tradicional, os autores deste trabalho chegaram a conclusão de que a ACT somada a outras habilidades podem levar a formação de um cidadão com discernimento crítico sobre a ciência e a tecnologia. (Fumeiro et al., 2019).

A escolha do artigo A023, se deu pela temática ser voltado realmente a uma situação do dia a dia do aluno, e a nosso ver se configura sim em uma forma de formação do cidadão, pois aborda o conhecimento popular sobre truques encontrados em vídeos na internet que tratam da limpeza doméstica. Este artigo teve o objetivo de analisar e discutir potencialidades do uso destes vídeos sob uma perspectiva da ACT no ensino de Química, e os autores mostram que os resultados mostraram que, o uso destes vídeos ajudou na elaboração de propostas pedagógicas e evidenciaram a formação de um cidadão consciente e crítico em relação ao uso da ciência (Silva \& Milaré, 2019).

E por último o artigo classificado com o código A028, teve o objetivo de buscar evidencias de que a ACT direcionada para a formação cidadã pode ser promovida por meio de uma ação dialógica. Os autores concluem que para a formação cidadã, e necessário passar por uma formação humanizada do homem, e para que ocorra deve-se reconstituir a essência do homem como indivíduo. E é necessário que a ciência não seja apresentada como fim, mas sim como meio para o conhecimento do mundo ((Lorenzon et al., 2020).

Os autores citados chegam a mesma conclusão que, para que haja a formação de um cidadão que tenha discernimento para poder compreender e até opinar sobre assuntos relacionados a ciência e a tecnologia, necessita ser alfabetizado cientificamente, e que o papel do ensino de ciências neste processo e importante, e é uma cobrança da sociedade atual, que é influenciada pelos avanços da ciência e da tecnologia.

Para Dantas e Deccache-Maia (2020), os professores e cientistas de qualquer área das ciências, devem se unir para combater a disseminação de notícias falsas, se utilizando para de isso de vários artifícios tipo: vídeos, textos, assim contribuindo para a divulgação científica e tornando a ciência mais acessível ao público leigo.

A Alfabetização Científica é uma das ações que podem ser tomadas para combater a proliferação das Fake News, quer dizer, educar a população para reconhecer a autenticidade das notícias verificando a fonte e percebendo possíveis modificações da notícia original, e principalmente intender a intenção da veiculação dessa notícia (Sousa Júnior et al., 2020).

A sociedade está refém de informações que chegam pelas mídias sociais, e somente ela pode procurar o discernimento para identificá-las, dizer qual é verdadeira e qual é falsa. A escola tem um papel importante para se chegar a ter esse entendimento, ajudando aos alunos a desenvolver o senso crítico para diferenciar notícias verdadeiras e notícias falsas (Busco \& Karat, 2019).

É indiscutível que há contribuição da ciência e da tecnologia ao desenvolvimento da sociedade atual. Pode-se dizer que que nos dias atuais as relações entre os conhecimentos científicos e tecnológicos e a sociedade é considerável. Porém acontecimentos contrários de oportunidades e limitações, de vantagens e riscos e de benefícios e males, que estão relacionados a ciência e tecnologia, aqui aponta-se a fake news, como um mal relacionado a ciência e a tecnologia, necessita-se de maior conhecimento relacionado as produções científicas e tecnológicas relacionadas a sociedade. Que nos faz ressaltar a necessidade de alfabetizar científica e tecnologicamente o cidadão (Firme \& Miranda, 2020). 


\section{Considerações Finais}

A descoberta do novo coronavírus, e as discussões sobre ele existentes mostra a necessidade de se levar a sociedade textos científicos. Mas não é só fazer chegar à sociedade texto com foco em assuntos científicos, mas também deve-se levar a sociedade o conhecimento necessário para que ao ler um texto científico possa-se compreender o mínimo do assunto abordado.

E para esse fim a Alfabetização Científica e Tecnológica que é inerente ao ensinar ciências, deve ser usada para formar um cidadão que possa ler e interpretar um artigo científico, ou que pelo menos possa compreender o que está lendo, ou seja, tenha um mínimo de conhecimento científico e tecnológico necessário para que possa opinar em assunto que tenham o foco na ciência e na tecnologia.

Que o cidadão alfabetizado cientificamente possa ler uma notícia disseminada sobre ciência, e possa saber procurar fontes fidedignas, que possam corroborar com a notícia e identificar como sendo verdadeira, ou que possa refutar e mostrar a notícia como uma notícia falsa.

Pode-se concluir que o cidadão alfabetizado nas ciências e tecnologias, terá o discernimento para avaliar se uma notícia é, uma notícia verdadeira, ou se é uma notícia falsa, ou como é mais conhecida uma Fake News. E com esta afirmação responde-se à pergunta que norteou este estudo. E afirmar que a Alfabetização Científica e Tecnológica da população em geral, pode ajudar a diminuir a crença em notícias falsas relacionadas a assuntos sobre ciências e tecnologia e consequentemente diminuir sua disseminação entre a população.

\section{Referências}

Braga, R. M. C. (2018). A Industria da Fake News e o Discurso de Ódio. In R. V. Pereira (Ed). Direitos Políticos, Liberdade de Expressão e Discurso de Ódio. $203-220$. IDDE.

Buskos, P. S. \& Karat, M. T. (2019). Ensino de Ciências: O Vírus Zica e as Fake News - Proposições para uma Prática Docente. Revista Teia, 20(57), 332 347. https://doi.org/10.12957/teias.2019.38798.

Chaves, T. S. S. \& Belli, N, C. J. (2020). SARS-COV-2, o Novo Coronavírus: Uma Reflexão sobre a Saúde Única (one health) e a Importância da Medicina de Viajem na Emergência dos Novos Patógenos. Revista Medicina, 9(1). https://doi.org/10.11606/issn.1679-9836.v99i1pi-iv.

Costa, E. M. \& Lorenzetti, L. (2020). A Promoção da Alfabetização Científica nos Anos Finais do Ensino Fundamental por meio de uma Sequência Didática sobre Crustáceos. Revista Brasileira de Ensino de Ciências e Matemática, 3(1), 11 - 47. https://doi.org/105335/rbecm.v3i1.10006.

Dutra, G. E., Oliveira, E. C., Del Pino, J. C. (2017). Alfabetização Científica e Tecnológica na Formação do Cidadão. Revista Signo, $38(2)$, 56 - 62. http://dx.doi.org/10.22410/issn.1983-0378.v38i2a2017.1375.

Firme, R. N. \& Miranda, R. D. (2020). Impactos de um Processo de Alfabetização Científica e Tecnológica de Licenciados em Química. Educación Química, 3(1), 115 - 126. http://dx.doi.org/10.22201/fq.18708404e.2020.1.

Fumeiro, C. L, Silveira, S. S. S., Martins, S. N., Silva, V. J. M. O. (2019). Alfabetização Científica e Tecnológica como Princípio da Formação do Cidadão. Revista de Estudos e Pesquisas sobre Ensino Tecnológico, 5(11), 150 - 162. https://doi.org/10.31417/educitec.v5i11.741.

Guan, W., Ni, Z., Hu, Y., Liang, W., Ou, C., He, J., Liu, L., Shan, H., Lei, C., Hui, D. S. C., Du, B., Li, L., Zeng, G., Yuen, K. Y., Chen, R., Tang, C., Wang, T., Chen, P., Xiang, J., ... Zhong, N. (2020). Clinical Charecteristics of Coronavirus Disease 2019 in China. The New England Journal of Medicine, 382, 1708 - 1720. https://www.nejm.org/doi/full/10.1056/NEJMoa2002032.

Herculano, V. C. \& Ferreira, L. C. (2015). A Concepção de Educação para Álvaro Vieira Pinto e sua Contribuição para Repensar Estudos sobre um Ensino Tecnológico Humanizador. Revista de Estudos e Pesquisa sobre Ensino Tecnológico, 1(1), 1 - 13. https://doi.org/10.31417/educitec.v1i01.22. http://dx.doi.org/10.22410/issn.1983-0882.v14i2a2017.1542.

Lins, E. S. \& Lopes, F. (2018). Trevas e Queda: Análise do Imaginário Feminino na Representação de Fake News sobre Marielle Franco. Revista Memorare, 5(1), 78 - 96. http://dx.doi.org/10.19177/memorare.v5e1201878-96.

Lorenzon, M., Oliveira, E. C., Del Pino, J. C. (2020). Possíveis Confluências entre Alfabetização Científica e Ação Dialógica nos Processos de Formação do Sujeito. Revista Thema, 17(1), 210 - 2020. http://dx.doi.org/10.15536/thema.v17.2020.210-220.1271.

Macedo, I. M., Omellas, J. L., Bomfim, H. F. (2020). COVID-19 No Brasil: O que se Espera para a População Subalternizada?. Revista Encantar - Educação, Cultura e Sociedade, 2, 01 - 10. http://dx.doi.org/10.46375/encantar.v2.

Marchesan, M. R. \& Kuhn, M. C. (2016). Alfabetização Científica e Tecnológica na Formação do Cidadão. Revista Thema, $13(3)$, 118 - 129. http://dx.doi.org/10.15536/thema.13.2016.118-129.380. 
Research, Society and Development, v. 11, n. 1, e17911124339, 2022

(CC BY 4.0) | ISSN 2525-3409 | DOI: http://dx.doi.org/10.33448/rsd-v11i1.24339

Melo, M. G., Neves, M. C. D., Silva, S. C. R. (2019). Alfabetização Científico-Tecnológica por meio de Letras de Músicas: Entendendo Visões de Ciência dethomas Kunh e Paul Feuerabend nas Metáforas de Raul Seixas. Revista Thema, 16(1), 24 - 34. http://revistathema.ifsul.edu.br/index.php/thema/article/view/1072

Ministério da Saúde. (2020, jun 26). Coronavírus. https://covid.saude.gov.br.

Monteiro, S., Pissaia, L. F., Lorenzon, M., Oliveira, E. C., Del Pino, J. C. (2017). Alfabetização Científica e Tecnológica como Possibilidade de Formação do Cidadão a partir de uma Abordagem da Educação em Saúde. Caderno Pedagógico, 14(2), 152-160.

Neto, M., Gomes, T. O., Porto, F. R., Rafael, R. M. R., Fonseca, M. H. S., Nascimento, J. (2020). Fake News no Cenário da Pandemia de COVID-19. Revista Cogitare Enfermagem, 25. http://dx.doi.org/10.5380/ce.v25i0.72627.

Niezer, T. M. (2012). Ensino de Soluções Químicas por meio da Abordagem Ciência-Tecnologia-Sociedade (CTS)[Dissertação de Mestrado]. Universidade Tecnológica Federal do Paraná.

Pissaia, L. F., Oliveira, E. C., Del Pino, J. C. (2017). A Escola Enquanto Ambiente de Formação cidadã: Uma Abordagem a partir da Alfabetização Científica e Tecnológica. Research, Society and Development, 6(4), 342-351. http://dx.doi.org10.17648/rsd-v6i4.150.

Rosa, T. F., Lorenzetti, L., Lambach, M. (2019). Níveis de Alfabetização Científica e Tecnológica na Avaliação de Química do Exame Nacional do Ensino Médio. Educação Química em Punto de Vista, 3(1), 1-26. https://doi.org/10.30705/eqpv.v3i1.

Sasseron, L. H. \& Carvalho, A. M. P. (2011). Alfabetização Científica: Uma Revisão Bibliográfica. Revista Investigação em Ensino de Ciências, 16(1), 59-77. https://www.if.ufrgs.br/cref/ojs/index.php/ienci/article/view/246.

Silva, L. A. R. \& Milaré, T. (2019). Truques Populares de Limpeza Domesticas: Potencialidades para a Alfabetização Científica e Tecnológica. Scientia Naturalis, 1(3), 355-368. https://periodicos.ufac.br/index.php/SciNat/article/view/2572.

Sociedade Brasileira de Pediatria. (2020, mai 10). Documento Científico: Novo Coronavírus (COVID-19). https://www.sbp.com.br/documentoscientificos/?tx_cwfiles\%5Bpage\%5D=8\&cHash=42803ed96fbdd30e55b073aeb6a39080.

Sousa Junior, J. H., Raash, M., Soares, J. C., Ribeiro, L. V. H. A. S. (2020). Da Desinformação ao Caos: Uma Análise das Fake News Frente à Pandemia do Coronavírus (COVID-19) no Brasil. Caderno de Prospecção, 13(3), 331-346. http://dx.doi.org/10.9771/cp.v13i2\%20COVID-19.35978.

Tapia, L. (2020). COVID-19 and Fake News in the Dominican Republic. The American Journal of Tropical Medicine and hygiene, 102(6), 1172-1174. https://doi.org/10.4269/ajtmh.20-0234.

Tuñas, I. T. C., Silva, E. T., Santiago, S. B. S., Mais, K. D., Silva-Júnior, G. O. (2020). Doença Pelo Coronavírus 2019 (COVID-19): Uma Abordagem Preventiva para a Odontologia. Revista Brasileira de Odontologia, 7, 1-7. http://dx.doi.org/10.18363/rbo.v77.2020.e1776.

World Health Organization. (2020, jun 26). CoronavirusvDisease (COVID-19) Pandemic. https://www.who.int/emergencies/diseases/novel-coronavirus-2019.

Zhu, N., Zhang, D. Wang, W., Li, X., Yang, B., Song, J., Zhao, X., Huang, B., Shi, w., Lu, R., Niu, P., Zhan, F., Ma, X., Wang, D., Xu, W., Wu, G., Gao, G. F., Phil, D., Tan, W. A. (2020). A Novel Coronavirus fron Patientes with Pneumonia in China, 2019. The New England Journal of Medicine, 382, 727-733. http://dx.doi.org/10.1056/NEJMoa2001017. 